\title{
- Abate humanitário de bovinos
}

\section{- Humane slaughter of cattle}

\section{Robertode 0liveiraRoça-CRMV-SP-n 2840}

Professor Adjunto da Disciplina de Tecnologia dos Produtos de Origem Animal UNESP/Botucatu/SP.

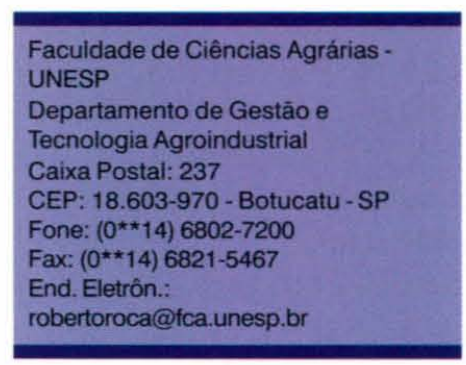

\section{RESUMO}

Abate humanitário pode ser definido como o conjunto de procedimentos técnicos e científicos que garantem o bem-estar dos animais desde o embarque na propriedade rural até a operação de sangria no matadouro-frigorífico. $\mathrm{O}$ abate de animais deve ser realizado sem sofrimentos desnecessários. As condições humanitárias devem prevalecer em todos os momentos precedentes ao abate. A insensibilização de animais é considerada a operação mais crítica durante o abate de bovinos. Tem por objetivo colocar o animal em estado de inconsciência, que perdure até o fim da sangria, não causando sofrimento desnecessário e promovendo uma sangria tão completa quanto possível. Neste artigo são abordados os temas referentes às operações ante-mortem, como transporte, manejo nos currais e operações de insensibilização e sangria e seus efeitos no bem-estar animal e na qualidade da carne.

Palavras-chave: abate de bovinos, bem-estar animal, manejo ante-mortem, transporte, insensibilização, sangria.

\section{Introdução}

$\mathrm{H}$ á algumas décadas, o abate de animais era considerado uma operação tecnológica de baixo nível científico e não se constituía em um tema pesquisado seriamente por universidades, institutos de pesquisa e indústrias. A tecnologia do abate de animais destinado ao consumo somente assumiu importância científica quando se observou que os eventos que se sucedem desde a propriedade rural até o abate do animal tinham grande influência na qualidade da carne (SWATLAND, 2000).

Nos países desenvolvidos há uma demanda crescente por processos denominados abates humanitários com o objetivo de reduzir sofrimentos inúteis ao animal a ser abatido (PICCHI e AJZENTAL, 1993; CORTESI, 1994). Abate humanitário pode ser definido como o conjunto de procedimentos técnicos e científicos que garantem o bemestar dos animais desde o embarque na propriedade rural até a operação de sangria no matadouro-frigorífico.

$\mathrm{O}$ essencial é que o abate de animais seja realizado sem sofrimentos desnecessários e que a sangria seja eficiente. As condições humanitárias não devem prevalecer somente no ato de abater e, sim, nos momentos precedentes ao abate (GRACEY e COLLINS, 1992).

Há vários critérios que definem um bom método de abate (SWATLAND, 2000):

a) os animais não devem ser tratados com crueldade;

b) os animais não podem ser estressados desnecessariamente;

c) a sangria deve ser a mais rápida e completa possível;

d) as contusões na carcaça devem ser mínimas;

e) o método de abate deve ser higiênico, econômico e seguro para os operadores.

Os métodos convencionais de abate de bovinos envolvem a operação de insensibilização antes da sangria, com exceção dos abates realizados conforme os rituais judaicos ou islâmicos (CORTESI, 1994).

É dever moral do homem, o respeito a todos os animais e evitar os sofrimentos inúteis àqueles destinados ao abate. Cada país deve estabelecer regulamentos em frigoríficos, com o objetivo de garantir condições para a proteção humanitária a diferentes espécies (CORTESI, 1994; LAURENT, 1997). 


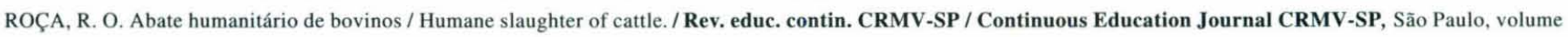
4, fascículo 2, p. $73-85,2001$.

O manejo do gado no frigorífico é extremamente importante para a segurança dos operadores, a qualidade da carne e o bem-estar animal. As instalações dos matadouros-frigoríficos bem delineadas também minimizam os efeitos do estresse e melhoram as condições do abate (GRANDIN, 1996, 2000a, 2000b, 2000d, 2000e, 2000f).

As etapas de transporte, descarga, descanso, movimentação, insensibilização e sangria dos animais são importantes para o processo de abate dos animais, devendo-se evitar todo o sofrimento desnecessário. Assim, o treinamento, a capacitação e a sensibilidade dos magarefes são fundamentais (CORTESI, 1994).

Os problemas de bem-estar animal estão sempre relacionados com instalações e equipamentos inadequados, "distrações" que impedem o movimento do animal, falta de treinamento de pessoal, falta de manutenção dos equipamentos e manejo inadequado (GRANDIN, 1996).

\section{Transporte de animais}

O transporte rodoviário é o meio mais comum de condução de animais de corte para o abate (TARRANT et al., 1988). No Brasil, o transporte também é realizado principalmente por via rodoviária, nos chamados "caminhões boiadeiros", tipo truque, com carroçaria medindo $10,60 \times 2,40$ metros, com três divisões: anterior com 2,65 x 2,40 metros, intermediária com 5,30 x 2,40 metros e posterior com 2,65 x 2,40 metros. A capacidade de carga média é de 5 animais na parte anterior e posterior e de 10 animais na parte intermediária, totalizando 20 bovinos.

O transporte rodoviário, em condições desfavoráveis, pode provocar a morte dos animais ou conduzir a contusões, perda de peso e estresse dos animais (KNOWLES, 1999).

A mortalidade de bovinos durante o transporte é extremamente baixa. Novilhos são mais susceptíveis que animais adultos (KNOWLES, 1995). Na África do Sul foi relatado $0,01 \%$ de mortalidade de bovinos em 1980, e $0 \%$, de um total de 22 mil animais transportados em 1990. Não há registro de mortalidade no transporte de bovinos no Reino Unido. Publicações mais antigas relatam que o transporte ferroviário é mais problemático que o transporte rodoviário (KNOWLES, 1999).

Os animais gordos são mais susceptíveis que os animais magros. As altas temperaturas, as maiores distâncias de transporte e a diminuição do espaço ocupado por animal também contribuem para que ocorram problemas de transporte (THORNTON, 1969).

A privação de alimento e água conduz à perda de peso do animal. A razão da perda de peso relatada na literatura científica é extremamente variável, de $0,75 \%$ a
$11 \%$ do peso vivo nas primeiras 24 horas de privação de água e alimento (WARRISS, 1990; KNOWLES, 1999). A perda de peso dos animais tem razão direta com o tempo de transporte, variando de $4,6 \%$ para 5 horas a $7 \%$ para 15 horas, recuperada somente após 5 dias (WARRISS et al., 1995). A perda de peso é motivada inicialmente pela perda do conteúdo gastrointestinal, e o acesso à água durante a privação de alimento reduz as perdas. A perda de peso da carcaça também é variável, de valores inferiores a $1 \%$ a valores de $8 \%$ após 48 horas de privação de alimento e água (WARRISS, 1990). O peso do fígado tende a diminuir rapidamente da mesma forma que o volume do rúmen, cujo conteúdo torna-se mais fluido (WARRISS, 1990).

Algumas propostas são recomendadas para a redução da perda de peso do animal e da carcaça que ocorre durante o transporte, como a utilização de soluções eletrolíticas via oral (SCHAEFER et al., 1997); no entanto, a administração de soluções injetáveis de vitaminas A, D e E não apresentam efeito na redução da perda de peso (JUBB et al., 1993b).

O principal aspecto a ser considerado durante o transporte de bovinos, é o espaço ocupado por animal, ou seja, a densidade de carga, que pode ser classificada em alta $(600 \mathrm{Kg} / \mathrm{m} 2)$, média $\left(400 \mathrm{Kg} / \mathrm{m}^{2}\right)$ e baixa $\left(200 \mathrm{Kg} / \mathrm{m}^{2}\right)$ (TARRANT et al., 1988). A Farm Animal Welfare Concil - FAWC (KNOWLES, 1999) dá uma fórmula para cálculo da área mínima a ser ocupada por animal, baseada no peso vivo: $\mathrm{A}=0,021 \mathrm{P}^{0,67}$, onde $\mathrm{A}$ é a área em metros quadrados e $\mathrm{P}$ o peso vivo do animal em quilos, recomendando a média de $360 \mathrm{~kg} / \mathrm{m}^{2}$. Randall, citado por KNOWLES (1999) preconiza outra equação: $A=0,01$ $\mathrm{P}=0,78$, e a "The Animal Welfare Advisory Committee", da Nova Zelândia, adota a equação de Randall como o mínimo espaço e a equação da FAWC como o máximo espaço (KNOWLES, 1999).

Teoricamente, do ponto de vista econômico, procura-se transportar os animais empregando alta densidade de carga, no entanto esse procedimento tem sido responsável pelo aumento das contusões e do estresse dos animais, sendo inadmissível densidade superior a $550 \mathrm{Kg} / \mathrm{m}^{2}$ (TARRANT et al., 1988, 1992). No Brasil, a densidade de carga utilizada é em média de 390 a $410 \mathrm{Kg} / \mathrm{m}^{2}$.

O aumento do estresse durante o transporte é proporcionado pelas condições desfavoráveis como privação de alimento e água, alta umidade, alta velocidade do ar e densidade de carga. (SCHARAMA et al., 1996). As respostas fisiológicas ao estresse, são traduzidas por hipertermia e aumento da frequiência respiratória e cardíaca. Com o estímulo da hipófise e adrenal, estão asso- 


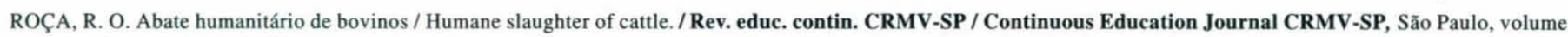
4, fascículo 2, p. $73-85,2001$.

ciados os aumentos do níveis de cortisol, glicose e ácidos graxos livres no plasma. Pode ocorrer ainda aumento de neutrófilos e diminuição de linfócitos, eosinófilos e monócitos (GRIGOR et al., 1999; KNOWLES, 1999; GRANDIN, 2000d).

Essas respostas fisiológicas aumentam nos animais transportados no terço final do veículo (TARRANT et al., 1988), na razão direta com a movimentação dos animais durante a viagem em estradas precárias (KENNY e TARRANT 1987) e em alta densidade de carga (TARRANT et al., 1992). O cortisol também sofre aumento na fase inicial, restabelecendo-se no decorrer do transporte (WARRISS, et al., 1995).

As operações de embarque e desembarque dos animais, se bem conduzidas, não produzem reações estressantes importantes (KENNY e TARRANT 1987). $\mathrm{O}$ ângulo formado pela rampa de acesso ao veículo em relação ao solo não deve ser superior a $20^{\circ}$, sendo desejável um ângulo de $15^{\circ}$ (CORTESI, 1994).

A extensão das contusões nas carcaças representa uma forma de avaliação da qualidade do transporte, afetando diretamente a qualidade da carcaça, considerando que as áreas afetadas são aparadas da carcaça, com auxílio de faca, resultando em perda econômica e sendo indicativo de problemas com o bem-estar animal (JARVIS e COCKRAM, 1994). A extensão das contusões aumenta com o aumento da densidade de carga, principalmente com valores superiores a $600 \mathrm{~kg} / \mathrm{m}^{2}$ (TARRANT et al., 1992).

A maior influência do transporte na qualidade da carne é a depleção do glicogênio muscular por atividade física ou estresse físico, promovendo uma queda anômala do $\mathrm{pH}$ post-mortem, originando a carne D.F.D. ("dark, firm, dry"). Essas condições estressantes são causadas pelo transporte prolongado (KNOWLES, 1999). Transporte por tempo superior a 15 horas é inaceitável do ponto de vista de comportamento e bem-estar animal (WARRISS, et al., 1995).

Um novo conceito de monitoramento on-line do transporte de animais é apresentado por GEERS et al. (1998) com o objetivo de verificar o bem-estar animal e melhorar a prevenção e o controle de doenças animais. O sistema, denominado de TETRAD - "Transport Animal Disease Prevention", é constituído de um sistema de telemetria e envio dos dados via satélite. $\mathrm{O}$ animal dispõe de um dispositivo eletrônico ("transponders") que fornece sua identificação, temperatura corporal e sua posição geográfica no veículo. $\mathrm{O}$ veículo possui um microcomputador (laptop) que transmite os dados do animal, via satélite, para uma central de controle, onde é realizado o monitoramento do transporte.

\section{Descanso e dieta hídrica}

O período de descanso ou dieta hídrica no matadouro é o tempo necessário para que os animais se recuperem totalmente das perturbações surgidas pelo deslocamento desde o local de origem até ao estabelecimento de abate (GIL e DURÃO, 1985).

De acordo com o artigo ${ }^{\circ} 110$ do RIISPOA - Regulamento de Inspeção Industrial e Sanitária de Produtos de Origem Animal (BRASIL, 1968), os animais devem permanecer em descanso, jejum e dieta hídrica nos currais por 24 horas, podendo esse período ser reduzido em função de menor distância percorrida. A Argentina também adota esse procedimento (ARGENTINA, 1971). As disposições oficiais portuguesas determinam também um mínimo de 24 horas para descanso dos animais nos currais (GIL e DURÃO, 1985). Na Austrália tem sido empregado o tempo de retenção de 48 horas, das quais 24 horas com alimentação e 24 horas em dieta hídrica (SHORTHOSE, 1991). No Canadá, o tempo de descanso é de 48 horas, com alimentação (GRANDIN e REGENSTEIN, 1994). De maneira geral, é necessário um período mínimo de 12 a 24 horas de retenção e descanso para que o gado que foi submetido a condições desfavoráveis durante o transporte por um curto período, recupere-se rapidamente. Os animais submetidos a essas mesmas condições, mas por período prolongado, exigirão vários dias para readquirirem sua normalidade fisiológica (THORNTON, 1969).

$\mathrm{O}$ descanso tem como objetivo principal reduzir o conteúdo gástrico para facilitar a evisceração da carcaça (THORNTON, 1969) e também restabelecer as reservas de glicogênio muscular (THORNTON, 1969; BARTELS, 1980; SHORTHOSE, 1991), tendo em vista que as condições de estresse reduzem as reservas de glicogênio antes do abate (BRAY et al., 1989).

Durante o período em que os animais permanecem em descanso e em dieta hídrica, é realizada a inspeção ante-mortem com as seguintes finalidades: a) exigir e verificar os certificados de vacinação e sanidade do gado; b) identificar o estado higiênico-sanitário dos animais para auxiliar, com os dados informativos, a tarefa de inspeção post-mortem; c) identificar e isolar os animais doentes ou suspeitos, antes do abate, bem como vacas com gestação adiantada e recém-paridas; d) verificar as condições higiênicas dos currais e anexos (BRASIL, 1968; STEINER, 1983; GIL e DURÃO, 1985; SNIJDERS, 1988).

Basicamente há cinco causas de problemas do bem-estar animal nos matadouros-frigoríficos (GRANDIN, 1996, 1996b): a) estresse provocado por equipa- 
mentos e métodos impróprios que proporcionam excitação, estresse e contusões; b) transtornos que impedem o movimento natural do animal, como reflexo da água no piso, brilho de metais e ruídos de alta freqüência; c) falta de treinamento de pessoal; d) falta de manutenção de equipamentos, como conservação de pisos e corredores; e) condições precárias pelas quais os animais chegam no estabelecimento, principalmente devido ao transporte. $\mathrm{O}$ bem-estar também é afetado pela espécie, raça, linhagem genética (GRANDIN, 1996) e pelo manejo inadequado como reagrupamento ou mistura de lotes de animais de origem diferente, promovendo brigas entre eles (ABATE, 1997; KNOWLES, 1999).

A retenção dos animais, o manejo adotado e as inovações que o animal recebe são causas de estresse psicológico, enquanto que os extremos de temperatura, fome, sede, fadiga e injúrias, são as principais causas do estresse físico (GRANDIN, 1997).

Os estudos para a determinação do nível de estresse em que o animal é submetido durante as operações ante-mortem apresentam resultados variáveis e de difícil interpretação para definição do bem-estar animal (GRANDIN, 1997, 1998, 2000g). As avaliações do estresse provocado no período ante-mortem devem ser realizadas na rampa de acesso ao boxe de insensibilização, ou no espaço reservado para o banho de aspersão.

\section{Banho de aspersão}

No Brasil, os animais após o descanso regulamentar seguem comumente por uma rampa de acesso ao boxe de atordoamento dotado de comportas tipo guilhotina. Nessa rampa é realizado o banho de aspersão. O local deve dispor, segundo o Ministério da Agricultura (BRASIL, 1968, 1971), de um sistema tubular de chuveiros dispostos transversal, longitudinal e lateralmente, orientando os jatos para o centro da rampa. A água deve ter a pressão não inferior a 3 atmosferas $\left(3,03 \mathrm{Kgf} / \mathrm{cm}^{2}\right)$ e recomenda-se hipercloração a $15 \mathrm{ppm}$ de cloro disponível. A Argentina adota método análogo (PIBOUL, 1973).

No Brasil, o afunilamento final da rampa de acesso é denominado "seringa", onde também há canos perfurados ou borrifadores, conforme artigo 146 do RIISPOA (BRASIL, 1968). A seringa simples ou dupla, até o boxe de atordoamento, deve ter, transversalmente, a forma "V", com a finalidade de permitir a passagem de apenas um animal por vez.

O banho de aspersão foi adotado em substituição ao banho de imersão, o qual, levando em conta a grande quantidade de sujeira que se depositava no tanque e a impossibilidade material de troca freqüente da água, cons- tituía-se em fator de disseminação e extensão de contaminações (MUCCIOLO, 1985).

O objetivo do banho do animal antes do abate é limpar a pele para assegurar uma esfola higiênica, reduzir a poeira, tendo em vista que a pele fica úmida e, portanto, diminuiria a sujeira na sala de abate (STEINER, 1983). O banho de aspersão antes do abate não afeta a eficiência da sangria nem o teor de hemoglobina retido nos músculos (ROÇA e SERRANO, 1995).

Para STEINER (1983), a limpeza de bovinos, particularmente suas extremidades, cascos e região anal, deve ser realizada nos currais, nas rampas ou nas seringas, utilizando mangueiras ou aspersão de água sob pressão. É recomendável que os animais permaneçam um pequeno espaço de tempo na rampa de acesso para secar a pele, tendo em vista que é impossível realizar uma esfola higiênica se o couro estiver úmido. $\mathrm{O}$ autor recomenda que dos bovinos que ainda apresentarem sujeiras aderidas, nessa fase do abate, somente as patas e os cascos devem ser aspergidos após o atordoamento.

$\mathrm{Na}$ rampa de acesso ao boxe de atordoamento, devem ser realizadas as avaliações do estresse provocado no período ante-mortem. GRANDIN (2000g) propõe avaliação dos deslizamentos e das quedas dos animais bem como das vocalizações ou mugidos dos animais na rampa de acesso ao boxe de insensibilização. A avaliação dos deslizamentos e das quedas (quando o animal toca com o corpo no piso) deve ser realizada, no mínimo, em 50 animais com a seguinte pontuação:

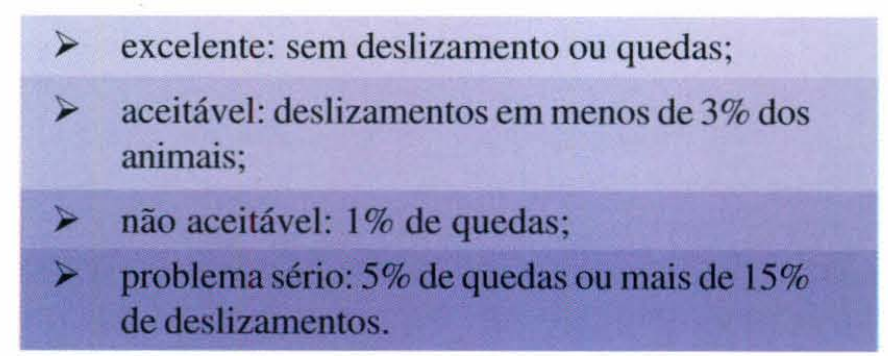

Com um manejo tranqüilo que proporcione bemestar dos animais torna-se quase impossível que eles escorreguem ou sofram quedas. Todas as áreas por onde os animais caminham devem, obrigatoriamente, possuir pisos não derrapantes (GRANDIN, 2000g).

As vocalizações ou mugidos são indicativos de dor nos bovinos. O número de vezes que o bovino vocaliza durante o manejo estressante tem relação com o nível de cortisol plasmático. A utilização do bastão elétrico para conduzir os animais é um dos motivos do alto índice de mugidos. A avaliação deve ser realizada, no mínimo, em 100 animais, também na rampa de acesso ao boxe de 


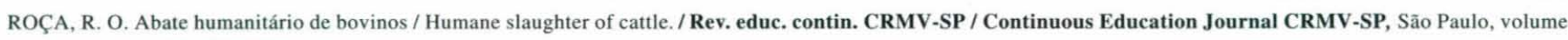
4, fascículo 2, p. 73 - 85, 2001.

insensibilização. O critério para avaliação, segundo GRANDIN (2000g) é:

excelente: até $0,5 \%$ dos bovinos vocalizam;

aceitável: $3 \%$ dos bovinos vocalizam;

inaceitável: 4 a $10 \%$ vocalizam;

problema sério: mais de $10 \%$ vocalizam.

A necessidade da utilização do bastão elétrico para conduzir os animais também constitui um sinal de que o manejo está inadequado. O bastão elétrico não deve ser utilizado nas partes sensitivas dos animais como olhos, orelhas e mucosas. Os bastões não devem ter mais que 50 volts. Ao reduzir o uso do bastão elétrico, melhorará o bem-estar animal. Os critérios para avaliar a utilização do bastão elétrico em bovinos, segundo GRANDIN (2000g) são (em \% de bovinos conduzidos com a utilização do bastão):

\begin{tabular}{|l|c|c|c|}
\hline & $\begin{array}{c}\text { rampa de acesso } \\
\text { ao boxe de } \\
\text { insensibilização }\end{array}$ & $\begin{array}{c}\text { entrada no } \\
\text { boxe de } \\
\text { insensibilização }\end{array}$ & $\begin{array}{c}\text { total de } \\
\text { bovinos }\end{array}$ \\
\hline Excelente & $0 \%$ & $\leq 5 \%$ & $\leq 5 \%$ \\
\hline Aceitável & $\leq 5 \%$ & $\leq 20 \%$ & $\leq 25 \%$ \\
\hline problema sério & - & - & $\geq 50 \%$ \\
\hline
\end{tabular}

\section{Métodos de insensibilização}

$\mathrm{O}$ atordoamento ou a insensibilização pode ser considerado a primeira operação do abate propriamente dito. Determinado pelo processo adequado, o atordoamento consiste em colocar o animal em um estado de inconsciência, que perdure até o fim da sangria, não causando sofrimento desnecessário e promovendo uma sangria tão completa quanto possível (GIL e DURÃO, 1985).

Os instrumentos ou métodos de insensibilização que podem ser utilizados são: marreta, martelo pneumático não penetrante (cash knocker), armas de fogo (firearm-gunshot), pistola pneumática de penetração ("pneumatic-powered stunners"), pistola pneumática de penetração com injeção de ar ("pneumatic-powered air injections stunners"), pistola de dardo cativo acionada por cartucho de explosão ("cartridge-fired captive bolt stunners"), corte da medula ou choupeamento, eletronarcose e processos químicos. $\mathrm{O}$ abate também pode ser realizado mediante a degola cruenta (método "kasher" ou "kosher") sem atordoamento prévio.

A marreta de insensibilização é largamente utilizada no Brasil, principalmente em estabelecimentos clandestinos. Há escassez de publicações sobre trabalhos experimentais com o uso da marreta em bovinos (LEACH, 1985). A utilização de marreta como método de abate promove grave lesão do tecido ósseo, com afundamento da região atingida. No encéfalo produz um processo de contusão cranioencefálica e não concussão, como relatado por vários pesquisadores. Apresentam também uma grande incidência de hemorragias macroscópicas e microscópicas na ponte e bulbo, podendo ser considerada lesão indireta, ou seja, uma hemorragia no ponto opositor do golpe no cérebro, promovida pelo contragolpe da porção basilar do osso occipital (ROÇA, 1999).

O martelo pneumático não penetrante leva a uma lesão encefálica ou injúria cerebral difusa provocada pela pancada súbita e pelas alterações da pressão intracraniana, resultando na deformação rotacional do cérebro, promovendo incoordenação motora, porém mantém atividade cardíaca e respiratória (LEACH, 1985; BAGER et al., 1990). O martelo pneumático, segundo LAMBOOY et al. (1981), não deve ser aceito como método de insensibilização em razão de sua baixa eficiência, que pode ser avaliada pela freqüência cardíaca, pela pressão sangüínea, pela respiração, pela presença de reflexos, pela eletroencefalografia e pela eletrocorticografia (FRICKER e RIEK, 1981; LAMBOOY et al., 1981; LEACH, 1985; BAGER et al., 1990, 1992). A eficiência do atordoamento com martelo pneumático só foi observada por LAMBOOY et al. (1981) em 50\% dos animais abatidos, ou seja, quando o atordoamento provocava uma hemorragia cerebral difusa.

As publicações sobre a utilização de armas de fogo ou pistolas pneumáticas também são escassas. A utilização de armas de fogo deve ser considerada uma operação de alto risco em matadouros-frigoríficos (LE$\mathrm{ACH}, 1985)$.

As pistolas pneumáticas de penetração fabricadas no Brasil possuem terminal em bastão de $11 \mathrm{~mm}$ de diâmetro com extremidade convexa e força de impacto de 8 a $12 \mathrm{Kg} / \mathrm{cm}^{2}$. Não possuem injeção direta de ar com o objetivo de laceração do tecido cerebral. A saída de ar no terminal do bastão tem como objetivo apenas auxiliar o retorno do dardo. O uso da pistola pneumática produz uma grave laceração encefálica, promovendo inconsciência rápida do animal e pode ser considerado um método eficiente de abate de bovinos (ROÇA, 1999). 
A pistola de dardo cativo acionada por cartucho de explosão é o método que tem recebido mais destaque nas publicações científicas. $\mathrm{O}$ dardo atravessa o crânio em alta velocidade (100 a $300 \mathrm{~m} / \mathrm{s})$ e força $\left(50 \mathrm{Kg} / \mathrm{mm}^{2}\right)$, produzindo uma cavidade temporária no cérebro. A injúria cerebral é provocada pelo aumento da pressão interna e pelo efeito dilacerante do dardo. Esse método é considerado o mais eficiente e humano para a insensibilização de bovinos, eqüinos e ovinos, (FRICKER e RIEK, 1981; GRACEY e COLLINS, 1992; LEACH, 1985; WORMUTH e SCHUTT-ABRAHAM, 1986; DALY et al., 1988), adotados também para suínos (DEPARTAMENT OF AGRICULTURE, USA, 1999) e aves (LAMBOOIJ et al., 1999).

A utilização de pistolas de dardo cativo (pneumática ou de explosão) provoca lesões do tecido do sistema nervoso central, disseminando-o pelo organismo animal. SCHMIDT et al. (1999) encontraram segmentos de tecido cerebral no ventrículo direito, em $33 \%$ dos animais abatido por pistola pneumática com injeção de ar; $12 \%$ dos animais abatidos por pistola pneumática sem injeção de ar e em 1\% dos animais abatidos por pistola de dardo cativo acionada por explosão.

O corte da medula era utilizado para o abate de búfalos, em razão da alta resistência da calota craniana, o que impede a inconscientização por outros processos mecânicos.

A eletronarcose e o dióxido de carbono são empregados somente para suínos, sendo inviável para bovinos (TROEGER, 1991; WOTTON et al., 1992).

Com exceção da eletronarcose e da insensibilização por dióxido de carbono, o sucesso de aplicação de uma técnica depende da habilidade do magarefe, que deve ser especialmente treinado para executar o atordoamento (LEACH, 1985).

O boxe de atordoamento é de construção metálica. $\mathrm{O}$ fundo e o flanco que confina com a área de vômito são móveis, possuindo, o primeiro, movimento basculante lateral, e o segundo, movimento de guilhotina, acionados mecanicamente e em sincronia, depois de abatido o animal. Assim ocasionam a ejeção desse animal para a área de vômito (BRASIL, 1971).

Após a insensibilização, o animal desliza sobre a grade tubular da área de vômito e é suspenso ao trilho aéreo por um membro posterior, com o auxílio de um gancho e uma roldana. Nesse momento, pode ocorrer regurgitação, devendo o local ter água em abundância para lavagem (MUCCIOLO, 1985).

$\mathrm{Na}$ canaleta de sangria deve ser observada a eficiência da insensibilização. Os sinais de uma insensibilização deficiente são: vocalizações, reflexos oculares presentes, movimentos oculares, contração dos membros dianteiros. GRANDIN (2000) adota o seguinte critério para análise do processo de insensibilização em bovinos:

$>$ excelente: menos que 1 por 1000 de animais insensibilizados parcialmente;

$>$ aceitável: menos que 1 por 500 de animais insensibilizados parcialmente.

Os únicos processos de atordoamento de animais previstos na Convenção Européia sobre Proteção dos Animais são:

a) meios mecânicos com a utilização de instrumentos com percussão ou perfuração do cérebro;

b) eletronarcose;

c) anestesia por gás.

Foram abolidas as técnicas da choupa, do prego ou estilete, do martelo de cavilha, da máscara de cavilha e armas de fogo. São exceções o abate segundo rituais religiosos e o abate de emergência (GIL e DURÃO, 1985). A concussão cerebral é permitida na Bélgica, França e Luxemburgo, porém proibida desde 1920 na Holanda (LAMBOOY et al., 1981; LEACH, 1985).

No Estado de São Paulo, foi aprovado, na Assembléia Legislativa, o Projeto de Lei no 297, de 1990 (SÃO PAULO, 1990), e, na Câmara dos Deputados, tramitou o Projeto de Lei $\mathrm{n}^{\circ}$ 3929, de 1989 (BRASIL, 1989), que dispõem sobre os métodos de abate de animais destinados ao consumo. Por eles, é permitido somente a utilização de métodos mecânicos por meio de pistolas de penetração ou pistolas de concussão, eletronarcose e métodos químicos com o emprego do dióxido de carbono, proibindo o uso da marreta ou choupa. O Projeto de Lei $\mathrm{n}^{\circ}$ 297 foi sancionado pelo Governador do Estado e publicado como Lei $n^{\circ} 7705$ (SÃO PAULO, 1992) de 19 de fevereiro de 1992, e foi regulamentado através do Decreto n. ${ }^{\circ}$ 39.972, de 17 de fevereiro de 1995 (SÃO PAULO, 1995); já o Projeto de Lei ${ }^{\circ} 3929$ foi vetado na Comissão de Agricultura da Câmara Federal, em 29 de outubro de 1991.

Em 1999, a Secretaria de Defesa Agropecuária do Ministério da Agricultura (BRASIL, 1999) apresentou a Instrução Normativa n. ${ }^{\circ} 17$, de 16 de julho de 1999, sobre regulamento técnico de métodos de insensibilização para o abate humanitário de animais de açougue, estabelecendo o prazo de 90 dias para sugestões ou críticas sobre a proposta apresentada. Após as sugestões realizadas pela comunidade científica, houve uma reunião na qual foi defini- 


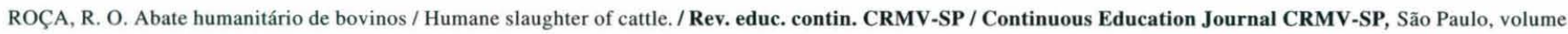
4, fascículo 2, p. $73-85,2001$.

do o Regulamento, sendo publicado em janeiro de 2000 (BRASIL, 2000).

\section{Ritual "Kasher"}

A religião judaica é a mais exigente quanto às normas de alimentação, que envolve seleção da matéria prima, abate de animais, preparo e consumo de alimentos, uso de determinados utensílios e também regras de alimentação em certos dias como "sabbath" ou dias de festas (LÜCK, 1994, 1995). Em contraste com a exigência religiosa, estes métodos têm sido criticados, tanto pela crueldade (REVISTA NACIONAL DA CARNE, 1995), como também pela falta de cuidados quanto aos aspectos higiênico-sanitários (LÜCK, 1994).

O abate "kasher" ou "schechita" envolve a contenção do animal, estiramento da cabeça por um gancho e uma incisão, sem movimentos bruscos, entre a cartilagem cricóide e a laringe (PICCHI e AJZENTAL, 1993), cortando a pele, músculos, traquéia, esôfago, veias jugulares e artérias carótidas (REGENSTEIN e REGENSTEIN, 1988) e às vezes chegando próximo às vértebras cervicais (SANZ EGANA, 1967). Essa operação tem como objetivo, segundo REGENSTEIN e REGENSTEIN (1988), permitir a máxima remoção de sangue.

O termo "kosher" ou "kasher" é utilizado para definir os alimentos preparados de acordo com as leis judaicas de alimentação (REGENSTEIN e REGENSTEIN, 1979, 1988; BARKMEIER, 1998; CHANIN e HOFMAN, 1998; KOF-K KOSHER SUPERVISION, 1998). As leis da alimentação judaica, denominada de "kashrut", são seguidas pelos membros da religião judaica (REGENSTEIN e REGENSTEIN, 1979, 1991; LÜCK, 1994, 1995), que atinge mais de seis milhões de pessoas nos Estados Unidos da América. Somente no Estado de Nova Iorque, EUA, com mais de dois milhões de judeus, o Departamento de Agricultura possui uma seção especial ("New York Agricultural and Market Law", parágrafo 201-a) responsável pela segurança e legitimidade dos alimentos comercializados como "kasher" ou "kosher". Os alimentos "kasher" representam nos Estados Unidos um mercado de US\$ 35 bilhões/ano, incluindo mais de 38 mil alimentos certificados como "kasher", produzidos por 9600 empresas do ramo de alimentos (STERN, 1990; SOJKA, 1995; KOSHER, 1997; AMERICAN MEAT INSTITUTE, 2000).

Os alimentos "kasher" não são somente adquiridos por judeus, mas também por muçulmanos, adventistas, vegetarianos, pessoas com alergias a certos alimentos e ingredientes e outros consumidores que simplesmente consideram subjetivamente o alimento "kasher" como de alta qualidade. São alimentos "kasher" a carne, o frango, o peixe com escamas, os laticínios, as frutas, os legumes e os produtos de confeitaria. Não são considerados "kasher" a carne suína, as misturas de carne e laticínios, o camarão, a lagosta e os frutos do mar (KHOLMEINI, 1979; LÜCK, 1994, 1995; IBEN, 1995; KOSHER, 1997; BARKMEIER, 1998). Problemas com Trichinella spiralis e Taenia solium provavelmente tenham sido responsáveis pela proibição judaica do consumo da carne suína (THORNTON, 1969), porém REGENSTEIN e REGENSTEIN (1979) afirmam que as leis que regem o ritual "kasher" não são "leis de saúde". As restrições alimentares, como a designação de animais puros e impuros; a proibição do consumo de misturas com carne e leite e consumo de sangue, são citadas na Bíblia (LEVÍTICO, 11: 1-19; ÊXODO, 22: 31, 23: 19; DEUTERONÔMIO, 12: 21-25; 14: 1-21).

"Schechita" é o ritual de abate dos animais para o preparo da carne "kasher". Ele é realizado por um magarefe denominado "schochet" que recebe treinamento por um longo período. A proposta do ritual é o corte das artérias carótidas e veias jugulares rapidamente, proporcionando rápida inconsciência e insensibilidade. $\mathrm{O}$ instrumento cortante utilizado para essa operação é chamado de "chalaf", o qual é afiado de forma eficiente e examinado após cada utilização. Cada seção de "schechita" é precedida por uma prece especial denominada "beracha". Quando são utilizados animais não domésticos, o sangue deve ser coberto por areia ou terra. A inspeção dos animais é realizada pelo "shochet", para verificação de moléstias, injúrias e, principalmente, a presença de aderências ou malformações, que condenarão o animal para o consumo (HOROVITZ, 1998; SHISLER, 2000). Os pulmões são inflados para verificação de aderências. No Brasil, os animais também são inspecionados pelo Serviço de Inspeção Federal.

Para a realização da degola, o animal é encaminhado ao boxe que é utilizado para atordoamento do abate não destinado à produção de carne "kasher", expõe uma das patas traseiras em um espaço de abertura, a qual é presa por uma corrente com roldana, o boxe é aberto, permitindo a saída do animal enquanto a corrente é suspensa por um guincho. O animal é baixado até seu dorso tocar o solo, mantendo seu posterior suspenso. Um gancho, na forma de "V" é colocado sobre a mandíbula e o pescoço é tensionado. $\mathrm{O}$ "shochet" apóia uma das mãos sobre o pescoço do animal, e por um movimento realizado com a "chalaf", 


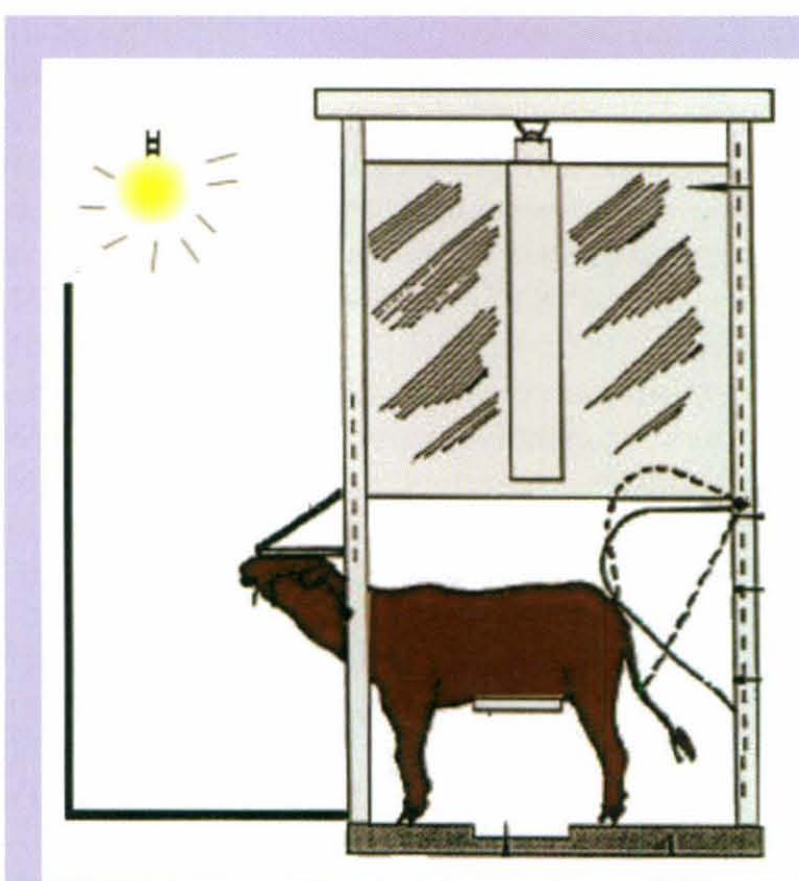

Figura 1. Esquema do boxe de contenção ASPCA.

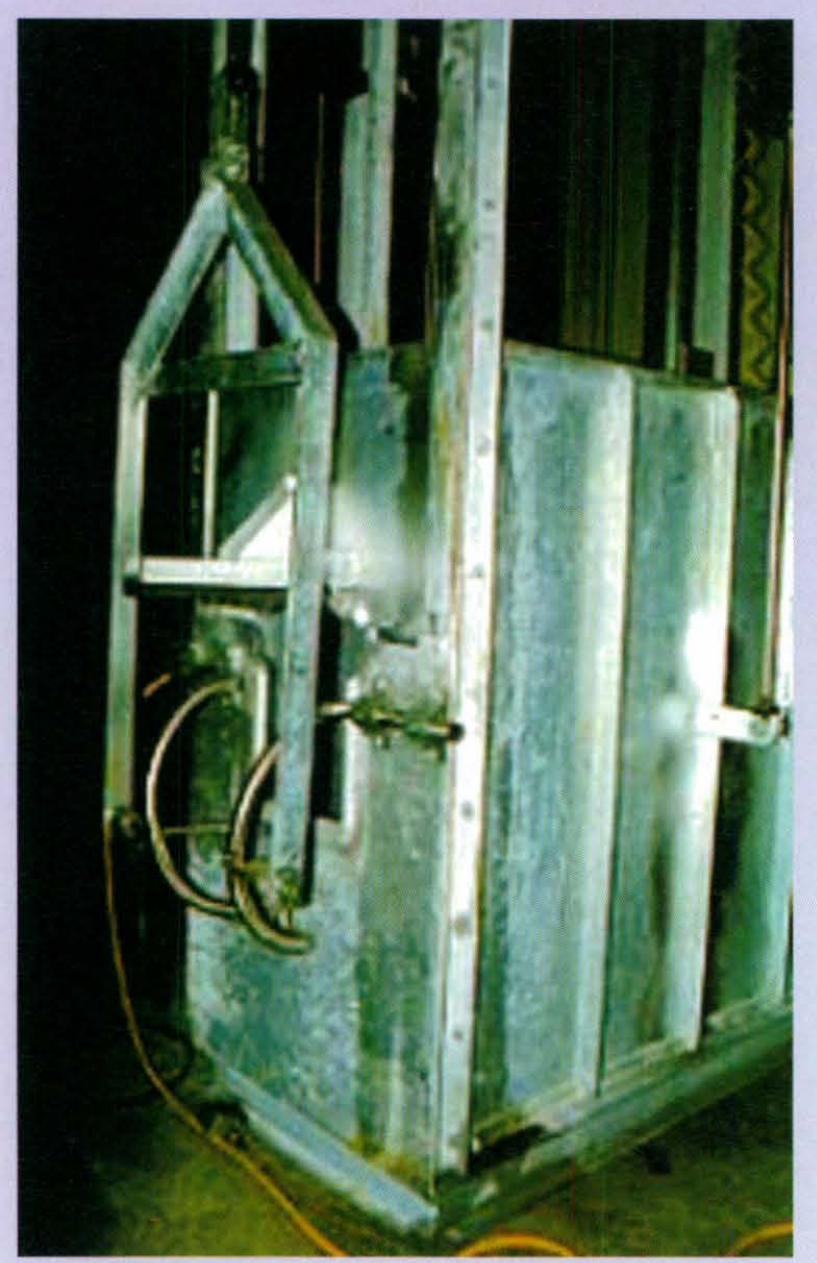

Figura 2. Modelo do boxe de contenção ASPCA. corta, entre o primeiro e o segundo anel da traquéia, a pele, as veias jugulares, as artérias carótidas, o esôfago e a traquéia, não podendo encostar o fio da faca nas vértebras cervicais. A incisão deve ser executada sem interrupção, sem movimentos bruscos, sem perfuração, sem dilacerações e nem sobre a laringe. Após a incisão, o animal é suspenso ao trilho, seguindo para o término da sangria e esfola (PICCHI e AJZENTAL, 1993; PICCHI, 1996).

O grande problema do ritual judaico de abate de bovinos no Brasil é o sistema de contenção dos animais, que é ineficiente e não considera que o gado abatido é principalmente o zebuíno, mais agitado que o taurino. A contenção e a degola cruenta provocam sérios efeitos estressantes nos animais abatidos pelo método "kasher". Nos momentos após a degola e suspensão, os animais abatidos por este ritual apresentam flexão dos membros anteriores e contração dos músculos da face, sinais evidentes de dor (ROÇA, 1999).

Analisando-se as alterações cranioencefálicas, o abate "kasher" não provoca lesão de tegumento e no crânio; nas meninges, ocorrem algumas hemorragias na aracnóide e pia-máter. No encéfalo podem ser encontradas congestão e algumas lesões microscópicas de hemorragia. A injúria cerebral provocada por esse método de abate é extremamente pequena e inferiores aos abates com a utilização da marreta ou pistola pneumática (ROÇA, 1999).

Tanto por razões humanitárias como de segurança, os frigoríficos que executam abate judaico devem instalar equipamentos modernos de contenção vertical. A prática de suspender os bovinos ou ovinos vivos deve ser eliminada. Vários esquemas e aparelhos de contenção são preconizados pela "American Society for the Prevention of Cruelty to Animals" (ASPCA) (GRANDIN, 2000b). A Figura 1 mostra o esquema de contenção de bovinos, e a Figura 2, o modelo ASPCA de boxe de contenção.

O aparelho consiste em um boxe estreito com abertura na frente para a cabeça do animal. Após a entrada do animal no boxe, um portão empurra-o para frente e um levantador abdominal é encostado debaixo do peito. A cabeça é contida por um levantador facial de maneira que o rabino possa executar a degola. O movimento do levantador abdominal deve ser restrito a 70 centímetros, de forma que não levante o animal do piso. O portão que empurra o traseiro deve estar equipado com um regulador de pressão separado, que permita ao operador regular a pressão exercida sobre o animal. O operador deve evitar o movimen- 


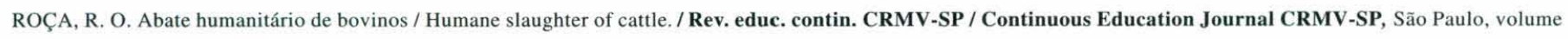

to brusco dos controles. Na maior parte dos casos o animal manter-se-á quieto e o boxe fecha-se devagar e, assim, menos pressão deverá ser exercida para a contenção perfeita (GRANDIN e REGENSTEIN, 1994; GRANDIN, 2000a).

Segundo a ASPCA (GRANDIN, 2000a), o boxe ASPCA pode ser instalado com facilidade, em um fim de semana, sem maior interrupção no frigorífico. Tem capacidade máxima de 100 cabeças de bovinos por hora e funciona eficientemente na razão de 75 animais/hora.

A carne "kasher" destinada ao consumo, deve ter poucos vasos sangüíneos e nervos. Os quartos dianteiros, carne de cabeça e costela são as partes mais consumidas entre os judeus. Há também proibição de consumo do nervo ciático (PICCHI e AJZENTAL, 1993). O preparo da carne, segundo o ritual "kasher", tem como objetivo eliminar o máximo de sangue. Consiste na imersão da carne em água por 30 minutos, seguida por salga a seco, com sal grosso, durante uma hora, seguida por três imersões consecutivas em água, cada uma, durante um período de uma hora (FOLHA DE SÃO PAULO 1992, 1992a; SHISLER, 2000).

\section{Sangria}

A sangria é realizada pela abertura sagital da barbela através da linha alba e pela secção da aorta anterior e veia cava anterior, no início das artérias carótidas e final das veias jugulares. O sangue é então recolhido pela canaleta de sangria (BRASIL, 1971). Deve-se cuidar para que a faca não avance muito em direção ao peito, porque o sangue poderá entrar na cavidade torácica e aderir à pleura parietal e às extremidades das costelas (THORNTON, 1969).

É conveniente a utilização de duas facas de sangria: uma para a incisão da barbela e outra para o corte dos vasos. As facas devem ser mergulhadas na caixa de esterilização após a sangria de cada animal, tendo em vista que microrganismos da faca já foram encontrados nos músculos e medula óssea (MUCCIOLO, 1985).

Algumas vezes, entretanto, há necessidade de utilização do sangue para fins comestíveis e este líquido deve ser colhido com facas especiais (tipo vampiro) conectadas diretamente nas artérias. Elas dispõem de um tubo conectado ao cabo da faca que, higienicamente, leva o sangue para recipientes esterilizados (PISKE, 1982).

$\mathrm{O}$ volume de sangue de bovinos é estimado em 6,4 a 8,2 litros/100Kg de peso vivo (BARTELS, 1980; KOLB, 1984). Para BARTELS (1980), a quantidade de sangue obtida na sangria com o animal deitado é aproximadamente de 3,96 litros/100 Kg de peso vivo e com a utilização do trilho aéreo é de 4,42 litros/100 Kg de peso vivo. Numa boa sangria, necessária para a obtenção de uma carne com adequada capacidade de conservação, é removido cerca de $60 \%$ do volume total de sangue, e o restante fica retido nos músculos $(10 \%)$ e vísceras (20 25\%) (PISKE, 1982; HEDRICK et al., 1994; SWATLAND, 2000).

O sangue tem $\mathrm{pH}$ alto $(7,35-7,45)$ (KOLB, 1984) e, em virtude do grande teor protéico, tem uma rápida putrefação (MUCCIOLO, 1985). Logo, a capacidade de conservação da carne mal sangrada é muito limitada. Além disso, constitui um problema de aspecto para o consumidor (BARTELS, 1980; HEDRICK et al., 1994). Portanto, a eficiência da sangria pode ser considerada uma exigência importante das operações de abate para obtenção de um produto de alta qualidade (WARRISS, 1977).

No entanto, existem controvérsias a respeito da relação entre sangria, higiene e aparência da carne. Sabese que o sangue de animais sãos é praticamente estéril e possui no plasma fatores com atividade antimicrobiana. Assim, a interrupção da sangria por hemostasia foi sugerida como um caminho para melhorar as propriedades sensoriais da carne como maciez, sabor, suculência e aparência (WILLIAMS, 1971, apud WARRISS, 1984).

Vários fatores são responsáveis pela eficiência da sangria. Podem ser citados o estado físico do animal antes do abate, o método de atordoamento e o intervalo entre $o$ atordoamento e a sangria. Todas as enfermidades que debilitam o sistema circulatório afetam a sangria. As enfermidades febris, agudas, provocam vasodilatação generalizada o que impede uma sangria eficiente. O mesmo é observado em animais abatidos em estado agônico, tendo em vista que o sistema circulatório está notadamente alterado (BARTELS, 1980; PETTY et al., 1994).

O banho de aspersão tem sido apontado como um procedimento capaz de melhorar a sangria pela vasocronstricção periférica que ele possa provocar (BARBOSA DA SILVA, 1995), porém, de acordo com ROÇA e SERRANO (1995), essa etapa do abate de bovinos não afeta a eficiência da sangria ou o teor de hemoglobina retido nos músculos.

Com relação aos efeitos dos métodos de insensibilização na eficiência da sangria, os trabalhos científicos têm sido direcionados principalmente para o abate de ovinos, com o emprego de eletronarcose, degola, pistola de dardo cativo e choupa.

Os resultados obtidos por diferentes autores são conflitantes em virtude do emprego de diferentes méto- 
dos para avaliação da eficiência da sangria. O emprego em ovinos da eletronarcose em contraste com degola cruenta, avaliada por CHRYSTALL et al. (1981) e eletronarcose com pistola de dardo cativo ou choupa, estudada por WARRISS e LEACH (1978), não apresentaram variações nos valores de hemoglobina residual na carne, porém PAULICK et al. (1989) encontraram uma menor quantidade de sangue colhido durante a sangria de ovinos submetidos à eletronarcose, quando comparados com animais submetidos ao atordoamento por pistola de dardo cativo.

Para bovinos, o método de abate afeta sensivelmente o processo de sangria, sendo a eficiência maior no abate "kasher" e menor no abate realizado mediante a insensibilização por pistola pneumática, seguida imediatamente pela estimulação elétrica (ROÇA, 1999).

$\mathrm{O}$ atordoamento do animal, por qualquer método, produz uma elevação da pressão sangüínea no sistema arterial, venoso e capilares, e dá um aumento transitório nos batimentos cardíacos (THORNTON, 1969), fatores que favorecem a sangria. $\mathrm{O}$ volume de sangue colhido também é maior se a sangria é realizada imediatamente após a insensibilização. A esse respeito, VIMINI et al. (1983, 1983a) estabeleceram que o volume de sangue colhido é inversamente proporcional ao intervalo entre o atordoamento e a sangria.

A importância da sangria imediata é evidente quando se verifica que a velocidade de um fluxo de um vaso cortado é 5 a 10 vezes mais rápida do que no vaso íntegro e somente depois de perder-se muito sangue é que a pressão sangüínea começa a cair (THORNTON, 1969).

Na Argentina, o intervalo máximo permitido é de dois minutos para bovinos (ARGENTINA, 1971) e, na Holanda, 30 segundos após eletronarcose em ovinos (LEACH, 1985). No Brasil, o Serviço de Inspeção Federal recomenda um intervalo máximo de 1 minuto (BRASIL, 2000).

Um problema relacionado com a sangria é o aparecimento de hemorragias musculares caracterizadas por petéquias, listras ou equimoses em várias partes da musculatura, provocadas por aumento da pressão sangüínea e ruptura capilar (THORNTON, 1969; LEACH, 1985). Vários fatores são responsáveis por essas alterações como o aumento do intervalo entre o atordoamento e a sangria (THORNTON, 1969), o estado de tensão dos animais no momento do abate (GIL e DURÃO, 1985), os traumatismos, as infecções e a ingestão de substâncias tóxicas (SMULDERS et al., 1989).

A eficiência da sangria pode ser definida como o volume de sangue residual ou retido nos músculos após o abate. A literatura sobre métodos de avaliação da eficiência da sangria é escassa. Talvez a dificuldade técnica para avaliar o sangue residual seja o fator principal dessa escassez de trabalhos científicos (WARRISS, 1977). Considerando uma variação individual muito acentuada no teor de hemoglobina sangüínea, ROÇA (1993) empregou a relação entre a hemoglobina sangüínea e a hemoglobina residual no músculo para estabelecer a eficiência da sangria, cujos resultados foram expressos em $\mathrm{ml}$ de sangue retido no músculo por $100 \mathrm{~g}$ de músculo.

\section{SUMMARY}

Humane slaughter can be defined as the set of technical and scientific procedures that assure the animals welfare from loading the trucks in the farm until the exsanguination in the slaughterhouse. Animals should be slaughtered without unecessary suffering and humane conditions should prevail at all times during the pre-slaughter management. Animal stunning is considered to be the most critical operation during slaughter as animals should be unconscious until the end of exsanguination, preventing suffering and assuring an efficient blood loss. This article presents aspects related to ante-mortem processing such as transport, pen management, stunning and exsanguination methods and their effect on animal welfare and meat quality.

Key words: cattle slaughter, animal welfare, handling, transport, stunning, exsanguination. 


\section{REFERENCIAS}

1. ABATE Humanitário (filme). Tradução de A. Escosteguy e J.S. Madeira. Porto Alegre: CRMV/RJ, 1997. 90 min, color, som, VHS.

2. AMERICAN MEAT INSTITUTE: AMI ONLINE. National Hot Dog e Sausage Council: answers to commonly asked questions about kosher products. 2000. 1 p. Disponível em: $\leq$ http:// meatami.org/HotKosh.htm>.

3. ARGENTINA. Ministério de la Agricultura y Ganaderia. Regulamento de inspección de productos, subproductos y derivados de origem animal: Decreto 4238/68 y normas legales conexas. Buenos Aires, 1971. 560 p.

4. BAGER, F.; BRAGGINS, T. J.; DEVINE, C. E. et al. Onset of insensibility at slaughter in calves: effects of electropletic seizure and exsanguination on spontaneous electrocortical activity and indices of cerebral metabolism. Research Veterinary Science, v. 52, n. 2, p. 162-173, 1992.

5. BAGER, F.; SHAW, F. D.; TAVENER, A. et al. Comparison of EEG and ECoG for detecting cerebrocortical activity during slaughter of calves. Meat Science, v. 27, n. 3, p. 211-225, 1990.

6. BARBOSA da SILVA, C. A. (Coord.) Matadouro misto de bovinos e suínos. Brasília: Ministério da Agricultura, do Abastecimento e da Reforma Agrária. Secretaria de Desenvolvimento Rural, 1995. 32 p.

7. BARKMEIER, S. Kosher diet. 1998. 1 p. Disponível em: $\leq \mathrm{http}: /$ /www.nd.edu/ theo/glossary/kosher.diet.html>.

8. BARTELS, H. Inspección veterinária de la carne. Zaragoza: Acribia, 1980. 491 p.

9. BRASIL. Câmara dos Deputados. Projeto de Lei no ${ }^{\circ} .3929$ de 1989. Dispõe sobre o abate de animais destinados ao consumo.

10. BRASIL. Ministério da Agricultura. Departamento de Defesa e Inspeção Agropecuária. Regulamento de Inspeção Industrial e Sanitária de Produtos de Origem Animal. São Paulo: Inspetoria do SIPAMA, 1968. 346 p. Disponível em: $\leq \mathrm{http}: / /$ www.bahianet.com.br/crmvba/riispoa2.htm>.

11. BRASIL. Ministério da Agricultura. Instrução Normativa $\mathrm{n}^{\circ}$. 17 , de 16 de julho de 1999. Regulamento técnico de métodos de insensibilização para o abate humanitário de animais de açougue. S.D.A./ M.A.A. Diário Oficial da União, Brasília, 20 jul. 1999. Sec. I p. $17-18$.

12. BRASIL. Ministério da Agricultura. Instrução Normativa $n^{\circ} .3$, de 07 de janeiro de 2000. Regulamento técnico de métodos de insensibilização para o abate humanitário de animais de açougue. S.D.A./ M.A.A. Diário Oficial da União, Brasília. 24 de jan. 2000. Sec. I. p. 14-16. Disponível em: <www.agricultura.gov.br/das/dipoa/ Anexo\%20Abate.htm>

13. BRASIL. Ministério da Agricultura. Padronização de técnicas, instalações e equipamentos. I- Bovinos. DNPA. DIPOA. 1971. 183 p.

14. BRAY, A. R.; GRAAFHUIS, A. E.; CHRYSTALL, B. B. The cumulative effect of nutritional, shearing and preslaughter washing stresses on the quality of lamb meat. Meat Science, Oxon, v. 25, n. 1 , p. $59-67,1989$.
15. CHANIN, M.; HOFMAN, E. G. What's kosher? 1998. 2 p. Disponível em: <http://bpe.com/food/recipes/kosher/index.html>.

16. CHRYSTALL, B. B.; DEVINE, C. E.; NEWTON, K. G. Residual blood in lamb muscles. Meat Science, v. 5, n. 3, p. 339-345, 1981.

17. CORTESI, M. L. Slaughterhouses and humane treatment. Revue Scientifique et Tecnnique Office International des Epizooties, v. 13, n. 1, p. 171-193, 1994.

18. DALY, C. C.; KALLWIT, E.; ELLENDORF, F. Cortical function in cattle during slaughter: conventional captive bolt stunning followed by exsanguination compared with shechita slaughter. Veterinary Record, v. 122, n. 2, p. 325-329, 1988.

19. DEPARTMENT OF AGRICULTURE. Animal Health Division. Regulation $\mathrm{n}^{\circ}$.146. Humane Slaughter methods. USA. 1998. 2 p. Disponível em: $\leq$ http://www.state.mi.us/execoff/admincode/data/ AC00285/s00146.txt>

20. FOLHA DE SÃO PAULO. O ritual do abate "Kasher". Folha de São Paulo, São Paulo, 28 mar. 1992. Cotidiano. p. 3-1.

21. FOLHA DE SÃO PAULO. São Paulo ganha abatedouro $100 \%$ Kasher. Folha de São Paulo, São Paulo, 1 set. 1992a. AgroFolha, p. 5-1.

22. FRICKER, C.; RIEK, W. Die Betäubung von Rinden vor dem Schlachten mit Hilfe des Bolzenschub-apparates. Fleischwirtchaft, v. 61, n. 1 , p. $124-127,1981$.

23. GEERS, R.; SAATKAMP, H. W.; GOOSSENS, K., et al. TETRAD: an on-line telematic surveillance system for animal transports. Computers and Electronics in Agriculture, v. 21, n. 1, p. 107-116, 1998

24. GIL, J. I.; DURÃO, J. C. Manual de inspeção sanitária de carnes. Lisboa: Fundação Caloustre Gulbenkian, 1985. 563 p.

25. GRACEY, J. F.; COLLINS, D. S. Humane Slaughter. In: Meat hygiene. London: Baillière Tindall, 1992. p. 143-167.

26. GRANDIN, T. Animal welfare in slaughter plants. In: CONFERENCE OF AMERICAN ASSOCIATION OF BOVINE PRACTITIONERS, 29, 1996. Proceedings... p. 22-26. Disponível em: <http:// www.grandin.com/welfare/general.session.html>. Acesso em: 2000 .

27. GRANDIN, T. Factors that impede animal movement at slaughter plants. Journal of American Veterinary Medical Association, v. 209 , n. 4 , p. $757-759,1996$ b.

28. GRANDIN, T. Assessment of stress during handling and transport. Journal of Animal Science, Champaing, v. 75, p. 249-257, 1997. Disponível em: <http://www.grandin.com/references/ handle.stress.html>. Acesso em: 2000.

29. GRANDIN, T. Objective scoring of animal handling and stunning practices at slaughter plants. Journal of American Veterinary Medical Association, v. 212, n. 1, p. 36-39, 1998.

30. GRANDIN, T. Guias recomendadas para el manejo de animais para empaquetadores de carne. 14 p. Disponível em: $\leq \mathrm{http}: / /$ www.grandin.com/spanish/spanish.0498.html>. Acesso em: 2000a. 


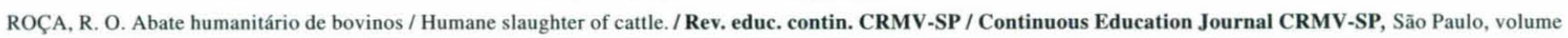
4 , fascículo 2, p. $73-85,2001$

31. GRANDIN, T. La conducta animal y su importancia en el manejo del ganado. 14 p. Disponível em:_http://www.grandin.com/spanish/spanish2.htm>. Acesso em: 2000b.

32. GRANDIN, T. Recommended ritual slaughter practices to improve animal welfare and employee safety. 2 p. Disponível em: $\leq \mathrm{http}: /$ /www.grandin.com/ritual/ritual.slaughter.tips.html $>$. Acesso em: 2000c.

33. GRANDIN, T. Buenas practicas de manejo para el arreo e insensibilización de animales.10p. Disponível em: \http:www.grandin.com/ spanish/buenas.practicas.html $>$. Acesso em: $2000 \mathrm{~d}$.

34. GRANDIN, T. Entendiendo la zona de vuelo. 5 p. Disponível em:

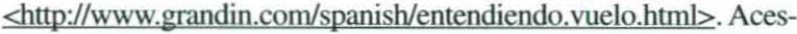
so em: $2000 \mathrm{e}$.

35. GRANDIN, T. Manejo y bienestar del ganado en los rastros. 19 p. Disponível em: <http://www.grandin.com/spanish/ tgbook.ch19.htm $>$. Acesso em: $2000 \mathrm{f}$.

36. GRANDIN, T. Manejo y procesado del ganado. 11 p. Disponível em: $\leq h t t p: / / w w w . g r a n d i n . c o m / s p a n i s h / g a n a d e r i a 94 . h t m l>$. Acesso em: $2000 \mathrm{~g}$.

37. GRANDIN, T.; REGENSTEIN, J. M. Religious slaughter and animal welfare: a discussion for meat scientists. Meat Focus International, CAB International, n. 3, p. 115-123, 1994. Disponível em:_http://www.grandin.com/ritual/kosher.slaugh.html>. Acesso em: 1999.

38. GRIGOR, P. N.; GODDARD, P. J.; LITTLEWOOD, C. A.; WARRISS, P. D.; BROWN, S. N. Effects of preslaughter handling on the behaviour, blood biochemistry and carcases of farmed red deer. Veterinary Record, v. 144, n. 9, p. 223-227, 1999.

39. HEDRICK, H. B.; ABERLE, E. D.; FORREST, J. C.; JUDGE, M. D.; MERKEL, R. A. Principles of meat science. 3. ed. Dubuque: Kendal/Hunt, 1994. 354 p.

40. HOROVITZ, R. Why keep kosher? 5 p. Disponível em: <http:/ /www.yatedneeman.co.il/jewishstudies/whykeepk.htm $>$. Acesso em: 1998.

41. IBEN, B. Das Schweinefleischverbot der semitischen Völker. Thesen und Argumente. Tierärztliche Umschau, v. 50, n. 10, p. 683694, 1995.

42. JARVIS, A. M.; COCKRAM, M. S. Effects of handling and transport on bruising of sheep sent directly from farms to salaughter. Veterinary Record, v. 135, n. 11, p. 523-527, 1994.

43. JUBB, T. F.; PINCH, D. S.; PETTY, S. R. Treatment with vitamin-A, vitamin-D and vitamin-E did not reduce weight in transported cattle. Australian Veterinary Journal, v. 43, n. 5, p. 171$173,1993 \mathrm{~b}$.

44. KENNY, F. J.; TARRANT, P. V. The physiological and behavioural responses of crossbred Friesian steers to short-haul transport by road. Livestock Production Science, v. 17, n. 1, p. 63-75, 1987.

45. KHOLMEINI, A. Princípios políticos, filosóficos, sociais e regiliosos. Rio de Janeiro: Record, 1979. 132 p.

46. KNOWLES, T. G. A review of post transport mortality among younger calves. Veterinary Record, v. 137, n. 16, p. 406-407, 1995.
47. KNOWLES, T. G. A review of the road transport of cattle. Veterinary Record, v. 144, n. 8, p. 197-201, 1999.

48. KOF-K KOSHER SUPERVISION. Glossary of terms. 2 p. Disponível em: <http://www.kof-k.com/gloss.htm>. Acesso em: 1998.

49. KOLB, E. Fisiologia veterinária. 4. ed. Rio de Janeiro: Guanabara Koogan, 1984. 612 p.

50. KOSHER certification a marketing plus. Food Technololy, v. 54, n. 5 , p. $67,1997$.

51. LAMBOOIJ, E.; PIETERSE, C.; HILLEBRAND, S. J. W. et al. The effects of captive bolt and electrical stunning, and restraining methods on broiler meat quality. Poultry Science, v. 78, n. 4, p. 600-607, 1999

52. LAMBOOY, E.; SPANJAARD, W.; EIKELENBOOM, G. Concussion stunning of veal calves. Fleischwirtchaft, v. 61, n. 1, p. 98-100, 1981.

53. LAURENT, H. R. H. P. The study of animal welfare: a moral obligation. In: ZUTPHEN, L. F. M.; BALLS; M. (Ed.). Animal alternatives, welfare and ethics. Amsterdam: Elsevier, 1997. p. 22-24.

54. LEACH, T. M. Pre-slaughter stunning. In: LAWRIE, R., (Ed.). Developments in meat science 3. London: Elsevier, 1985. p. 51-87.

55. LÜCK, E. Jüdische Speisegesetze. Ernährungs-Umschau, v. 41, n. 10 , p. $384-388,1994$

56. LÜCK, E. Zusatzstoffe für Lebensmittel und Bedarfsgegenstände im Lichte der jüdischen Speisegesetze. Deutsche LebensmittelRundschau, v. 4, n. 1, p. 115-117, 1995.

57. MUCCIOLO, P. Carnes: estabelecimentos de matança e de industrialização. São Paulo: Íncone, 1985. 102 p.

58. PAULICK, C.; STOLE, F. A.; Von MICKWITZ, G. The Influence of different stunning methods on the quality of sheep meat. Fleischwirtschaft, v. 69 , n. 2, p. 227-230, 1989.

59. PETTY, D. B.; HATTINGH, J.; GANHÃO, M. F.; BEZEUIDENHOUT, L. Factors which affect blood variables of slaughetered cattle. Tydskr. S. Afr. Veterinary Ver., v. 65, n. 2, p. 41-45, 1994.

60. PIBOUL, M. Técnicas e processos para conservação de carnes e tecnologia de derivados cárneos. Campinas: Fundação Tropical de Pesquisas e Tecnologia e Publitec S.A.E.C. y M., 1973. 335 p.

61. PICCHI, V Insensibilização no abate de bovinos. Revista Nacional da Carne, v. 21, n. 236, p. 38-44, 1996.

62. PICCHI, V.; AJZENTAL, A. Abate bovino segundo o ritual judáico. Revista Nacional da Carne, v. 18, n. 202, p. 53-57, 1993.

63. PISKE, D. Aproveitamento de sangue de abate para alimentação humana. I. Uma revisão. Boletim do Instituto de Tecnologia de Alimentos, Campinas, v. 19. n. 3, p. 253-308, 1982.

64. REGENSTEIN, J. M.; REGENSTEIN, C. E. An introduction to the kosher dietary laws for food scientists and food processors. Food Technology, v. 33, n. 1, p. 89-99, 1979.

65. REGENSTEIN, J. M.; REGENSTEIN, C. E. The kosher dietary laws and their implementation in the food industry. Food Technology, v. 42, n. 6, p. 86-94, 1988. 


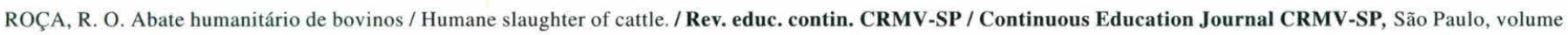
4, fascículo 2, p. $73-85,2001$.

66. REGENSTEIN, J. M.; REGENSTEIN, C. E. Current issues in kosher foods. Trends in Food Science Technology, n. 3, p. 50$54,1991$.

67. REVISTA NACIONAL DA CARNE. Abate humanitário: não há nenhuma razão para que o Governo demore para liberar a lei. Revista Nacional da Carne, v. 19, n. 215, p. 52-60, 1995.

68. ROÇA, R. O. Influência do banho de aspersão "ante-mortem" em parâmetros bioquímicos e microbianos da carne bovina. 1993. 185 f. Tese (Doutorado em Engenharia de Alimentos, Área de Tecnologia de Alimentos) - Faculdade de Engenharia de Alimentos - Universidade Estadual de Campinas, Campinas.

69. ROÇA, R. O. Abate humanitário: o ritual kasher e os métodos de insensibilização de bovinos. 1999. 232 f. Tese (Livredocência em Tecnologia dos Produtos de Origem Animal) - Universidade Estadual Paulista, Botucatu.

70. ROÇA, R. O.; SERRANO, A. M. Influência do banho de aspersão ante-mortem em parâmetros bioquímicos e na eficiência da sangria da carne bovina. Pesquisa Agropecuária Brasileira, v. 30, n. 8, p. $1107-1115,1995$.

71. SANZ EGAÑA. Enciclopedia de la carne. Madrid: Espasa-calpe, 1967. $1095 \mathrm{p}$.

72. SÃo PAULO. Assembléia Legislativa do Estado de São Paulo. Projeto de Lei ño 297 de 30 de maio de 1990. Dispõe sobre métodos de abate de animais destinados ao consumo. Diário Oficial do Estado de São Paulo, São Paulo, v. 100, n. 101, 1 jul. 1990. Sec. I.

73. SÃO PAULO. Lei n ${ }^{\circ} .7 .705$ de 19 de fevereiro de 1992. Estabelece normas para abate de animais destinados ao consumo e dá providências correlatas. Diário Oficial do Estado de São Paulo, São Paulo, v. 102, n. 36, p. 1, 20 fev. 1992. Sec. I.

74. SÃO PAULO. Decreto no. 39.972, de 17 de fevereiro de 1995. Regulamenta a Lei nr. 7.705 de 19 de fevereiro de 1992. Estabelece normas para abate de animais destinados ao consumo. Diário Oficial do Estado de São Paulo, São Paulo, v. 105, n. 35, p. 2-3, 18 fev. 1995. Sec. I.

75. SCHAEFER, A. L.; JONES, S. D. M.; STANLEY, R. W. The use of electrolytic solutions for reducing transport stress. Journal of Animal Science, v. 75, n. 1, p. 258-265, 1997.

76. SCHARAMA, J. W.; van der HEL, W.; GORSSEN, J., et al. Required thermal thresholds during transport of animals. The Veterinary Quartely, v. 18, n. 3, p. 90-95, 1996.

77. SCHMIDT, G. R.; HOSSNER, K. L.; YEMM, R. S. et al. An enzyme-linked immunosorbent assay for glial fibrillary acidic protein as an indicator of the presence of brain or spinal cord in meat. Journal of Food Protection, v. 62, n. 4, p. 394-397, 1999.

78. SHISLER, G. The Jewish dietary laws. 2 p. Disponível em: $\leq$ http://www.ort.org/anjy/therev/kashrut.htm>. Acesso em: 2000.

79. SHORTHOSE, W. R. Experiência australiana na utilização do búfalo para carne. In: SIMPÓSIO SOBRE BÚFALO COMO PRODUTOR DE CARNE, 1. 1991, Campinas. Palestra... Campinas, 1991.

80. SMULDERS, F. J. M.; EIKELENBOOM, G.; LAMBOOY, E. et al. Electrical stimulation during exsanguination, effects on the prevalence of blood splash and sensory quality characteristics in veal. Meat Science, v. 26, n. 2, p. 89-99, 1989.
81. SNIJDERS, J. Good manufacturing practices in slaughter lines. Fleischwirtschaft, v. 68, n. 6, p. 753-756, 1988.

82. SOJKA, K. Bundesverwaltungsgericht: Schächten darf nicht erlaubt werden. Tierärztliche Umschau, v. 50, n. 10, p. 728-729, 1995.

83. STEINER, H. Working model of standardized technique for the hygienic slaughtering of cattle. Fleischwirtschaft, v. 63, n. 7, p. 1186-1187, 1983.

84. STERN, M. D. Kosher food and the law. Judaism, v. 39, p. 398401, 1990.

85. SWATLAND, H. J. Slaughtering. 10 p. Disponível em: $\leq h t t p: / /$ www.bert.aps.uoguelph.ca/ $\sim$ swatland/ch1.9.htm $>$. Acesso em: 2000.

86. TARRANT, P. V.; KENNY, F. J.; HARRINGTON, D. The effect of stocking density during 4-hour transport to slaughter on behaviour, blood constituents and carcass bruising in Friesian steers. Meat Science, v. 24, n. 3, p. 209-222, 1988.

87. TARRANT, P. V.; KENNY, F. J.; HARRINGTON, D.; MURPHY, M. Long distance transportation of steers to slaughter: effect of stocking density and physiology, behaviour and carcass quality. Livestock Production Science, v. 30, n. 3, p. 223-238, 1992.

88. THORNTON, H. Compêndio de inspeção de carnes. Londres: Baillière Tindall an Cassel, 1969. 665 p.

89. TROEGER, K. Slaughtering: animal protection and meat quality. Current practice - What needs to be done? Fleischwirtschaft, v. 71, n. 3, p. 298-302, 1991.

90. VIMINI, R. J.; FIELD, R. A.; RILEY, M. L. et al. Effect of delayed bleeding after captive bolt stunning on heart activity and blood removal in beef cattle. Journal of Animal Science, v. 57, n. 3, p. 628-631, 1983.

91. WARRISS, P. D. The residual blood content of meat. A review. Journal of Science Food Agriculture, v. 28, n. 5, p. 457-462, 1977.

92. WARRISS, P. D. Exsanguination of animals at slaughter and the residual blood content of meat. Veterinary Record, v. 115, n. 12, p. $292-295,1984$.

93. WARRISS, P.D. The handling of cattle pre-slaughter and its effects on carcass meat quality. Applied Animal Behaviour Science, v. 28, n. 9, p. 171-186, 1990.

94. WARRISS, P. D.; LEACH, T. M. The influence of slaughter method on the residual blood content of meat. Journal of Science Food Agriculture, v. 29, n. 1, p. 608-610, 1978.

95. WARRISS, P. D.; BROWN, S. N.; KNOWLES, T. G.; KESTIN, S. C.; EDWARDS, J. E.; DOLAN, S. K.; PHILIPS, A. J. Effects on cattle of transport by road up to 15 hours. The Veterinary Record, v. 136, n. 1, p. 319-323, 1995.

96. WORMUTH, H. J.; SCHUTT-ABRAHAM, I. S. Zur tierschutzerischen, fleischygiemischen und rechtlichen Problematik einer mit der Tötung zusammenfallenden Betäubung von schlachttieren. Fleischwirtschaft, v. 66, n. 3, p. 1420-1424, 1986.

97. WOTTON, S. B.; ANIL, M. H.; WHITTINGTON, P. E. et al. Pig slaughtering procedures: Head-to-back stunning. Meat Science, v. 32, n. 3, p. 245-255, 1992. 